\title{
Predicting Sales Revenue by Using Artificial Neural Network in Grocery Retailing Industry: A Case Study in Turkey
}

\author{
Dilek Penpece and Orhan Emre Elma
}

\begin{abstract}
Forecasting sales quantity and sales revenue is very vital for a company to take action for the next period for sustainable competition. It is especially important for growing industries like grocery retailing industry. Turkey's grocery retailing industry is evolving rapidly. Due to increasing importance; the aim of this study is to forecast the sales revenue of grocery retailing industry in Turkey with the help of grocery retailers marketing costs, gross profit, and its competitors' gross profit by using artificial neural network. Artificial neural networks are models which are used for forecasting because of their capabilities of pattern recognition and machine learning. ANN method is used to forecast the sales revenue of upcoming period. According to results there are high similarities between forecasted and actual data. Forecasted results of this study are bigger or smaller than the actual data for only $10 \%$. Because of this high accuracy, companies at grocery retailing industry in Turkey can use ANN as a forecasting tool.
\end{abstract}

Index Terms-Sales revenue, forecasting sales revenue, grocery retailing industry, artificial neural network.

\section{INTRODUCTION}

Globalization differentiates the business environment, provokes competition among companies and even countries. Today's business environment forces companies to maintain and sustain competitive advantage that can results with profitability. Marketing has a crucial part in competition and companies which effectively manage costs can make stable profits. Forecasting sales quantity and sales revenue is very vital for a company to take action for the next period. Sales forecast enable companies to manage their budget effectively, to minimize uncertainty, to reduce risks, to speed up the decision making process etc. For this reason some techniques are used for years.

Focusing on grocery retailing has been increasing rapidly especially in developing countries like Turkey due to the supermarket radical changes. Grocery retailing industry is an organic, active and highly competitive industry; it's evolving every single day. With the economy seemingly emerging from the crises, industry leaders are looking for a picture of what is ahead of them. In this respect, declaring the sales forecasts in grocery retailing industry in Turkey is important more than ever.

Manuscript received April 9, 2014; revised July 10, 2014.

The authors are with Adana Science and Technology University, Adana, Turkey (e-mail: dpenpece@adanabtu.edu.tr, oeelma@adanabtu.edu.tr).

\section{NEURAL NETWORK}

Artificial neural networks (ANN) can be defined as a highly connected array of elementary processors called neurons [1]. According to Specht, ANN is usually defined as a network composed of a large number of simple processors (neurons) that are massively interconnected, operate in parallel, and learn from experience (examples) [2]. At information processing and pattern identification, ANN's are used. It takes its roots from the working mechanism of human brains. At this model, like human brains, there are neurons which are computing units, and they are interconnected with each other in an organized fashion. Neurons process information and convert inputs into outputs. According to the relationship between these neurons, reliable information can be generated [3]. It is a simplistic form of the neural system at human brains, but if inputs have a strong connection than notable information can be achieved.

One major application area of ANNs is forecasting for both researchers and practitioners [4]. The neural network approach produces better classification, handles complex underlying relationships better, and is stronger at interpolation [5]. ANNs have a high modelling flexibility and adaptability, as they can control the learning process. On the other hand it can adjust their parameters if new input data are available [6]. Using ANN in studies has its own benefits to some extent.

Different neural system models have been created for different applications. The most used neural network is feed forward neural network. At this type there are three layers, which are; input layer, hidden layer, and output layer. At input layer, different independent variables are used to forecast output layer, which consists of dependent variable. At hidden layer, neurons are interconnected to input and output layers. This is used for examining the pattern at nonlinear relationships between output and input layers [3]. Because at our study there is linear relationship between inputs and outputs, hidden layer is not used. The type which doesn't contain hidden layer in ANN is called single-layer perceptron. Inputs are simply connected with outputs via weights. According to Sexton and Dorsey, criticisms are generally focused on the inability to adequately identify identify unnecessary weights in the solution [7]. This limits to reach a strong output but some algorithms are created to eliminate this problem.

ANN should be trained before forecasting process implemented. Neural networks give weights to connections at the training process. The overall better performance of 
ANN could be related to the assertion that ANN is better able to handle non-linearities in the data [8]. Training process tries to create a learning algorithm in order to forecast outputs in ANN. So ANN use this learning algorithm in the process.

Forecasting problems arise in so many different disciplines and the literature on forecasting that use ANNs is scattered in so many diverse fields. It is hard for a researcher to be aware of all the work done to date in the area [4]. ANNs have increasingly been used in many disciplines from the early 1980 s to recent years such as engineering, medical diagnosis, data mining, and corporate business available [6]. For example ANN is used in data mining [9]. There are other areas that ANN's are successful, and these include competitive market structuring, market segmentation analysis, identification of loyal and profitable customers, also forecasting brand shares etc. [10]-[15]. ANN models are increasingly being used as a decision aid. Number of areas such as manufacturing, marketing, and retailing used it [16]. Several authors have given comprehensive reviews of neural networks, examples of its applications, and comparisons with the statistical approach [11], [17].

\section{NeUral Network In Forecasting SALES}

Marketing costs are very essential when maximizing profits. An effective business should cut costs. But if a business wants to reach more customers an efficient advertising budget can help reaching this goal. In developing countries, if a business is working efficiently, when advertising costs, as a means of marketing costs, are increased, generally its net profits increased [18]. Dekimpe and Hannsens's study examined the relationship between marketing expenditures and sales performance [19]. The empirical evidence in this study suggests that advertising has strong effects on almost all sales. Especially for big companies the advertising cost has a crucial place as a means of marketing expenditures. But it is not sufficient to use just advertising in forecasting sales as a marketing cost.

Compared to 50 years from now, marketing costs have been increasing dramatically from $20 \%$ to $50 \%$. As a result, companies want to make the most of their marketing costs. In order to employ a good strategy, companies have to make sure that suitable marketing efforts are directed towards right target customers. This situation can increase productivity [20]. On the other hand the rate of increase in marketing cost may not effect sales revenue simultaneously. So in order to maintain effective sales management companies should balance their marketing costs with sales revenue at an optimum level.

The marketing costs that passed over to the customers have always been criticized over the years. Critics said that the prices could be lower if less money were spent for marketing. But when inflation and time factor has taken into consideration, this hypothesis is not true. In 1950 the average price of carpeting In the US was \$6.02, but by the time 1992 the price was came to $\$ 6.27$ and quality has also risen. The price is very low when inflation effect has put into consideration [21]. In order to fact that price increases is not always the result of marketing cost, there are other factors effecting this situation.
Effective sales forecasting, results in appropriate marketing costs and maximum sales revenue. This forecast is very vital for companies. Good forecast can reduce production and material costs, and gives competitive advantage on sales prices [22]. As a result low inventory level goals can be reached and efficient Just-in-time (JIT) delivery occurs. JIT can used for cost minimization especially in grocery retail industry. Exploring retail demand is very important for retailers, because inventory management is essential for maximizing revenue and gaining a competitive position in the industry [16]. In order to control JIT delivery, the marketing department should estimate sales quantity. Marketing, material and production departments should work as a team to specify the needs of the company for next quarter, and take necessary action. This coordination results in reduction of the operating costs.

On the other hand market share is positively correlated with profits. According to Johnson and Scholes, gaining and maintaining higher market share results in higher profitability. The market share is important in nationally as well as internationally [23]. If a company's market share in a given growing sector increases then it is possible that its gross profit rises. So we determine the gross profit as a variable that can affect the sales revenue in retailing. Gross profit can be obtained by subtracting cost of goods sold from total sales. It is directly related with sales. In order to maintain and increase profitability, a company should increase its sales higher than its cost of goods sold.

Retailing sector is rapidly growing in Turkey. The total volume of the retail sector has almost tripled in 5 years, from US $\$ 70$ billion in 2005 to US $\$ 187$ billion in 2010 . By the year 2014, this sector is expected to reach US $\$ 250$ billion. The number of modern shopping malls in Turkey doubled in five years, from 129 in 2006 to 291 in 2011. 2.1 million employees find their jobs in this industry, and total retail area used for this sector is at least 23 million square meters. Turkey is the 7th largest retail market in Europe and the tenth in the world [24]. So it is assumed that as a variable of forecasting gross profit is strongly related to sales revenue at grocery retailing industry in Turkey as a growing sector.

Retail industry companies compete with each other in different ways. Food retailing has also a big potential within retailing sector and intensive competition exists in food retailing. Food retailers try to gain a competitive advantage against their rivals with their product selection and type, offered service types and their quality, discount policies etc. According to Zhu et al. [25] an appropriate characterization of expected revenues would require correct measurement of the importance of competition in a market. At this study, BİM is a hard discount retailer, which generally produces its own products and sells them at a fairly discounted price. Migros is the first grocery retailer in Turkey, and this company operates in almost every segment for grocery retailing and also implemented the online grocery shopping. Carrefour, is a major player in Europe and also in Turkey. This company can be considered as multi format retailer, which attracts different types of customers according to their needs.

So it is expected that competitors' gross profit will affect the sales revenue of each company in grocery retailing industry as a steady market. 
In order to forecast sales revenue gross profit, competitors' gross profit and marketing costs are put into account in this study. Some studies focused on exploring sales quantity by the help of time series [26]-[28]. According to Thall, when forecasting the retail demand, grocery products industry uses artificial neural networks [29]. Lots of analysis can be used for forecasting sales revenue such as time series, regression analysis and artificial neural network. As explained earlier gross profit, competitors' gross profit and marketing costs are strongly related to sales revenue. Because of the fact that if inputs have a strong connection than notable information can be achieved in artificial neural network, ANN is preferred over time series and regression analysis in this study.

\section{Methodology}

The structure of the food retailing sector in Turkey is largely based on micro-grocers which are basically founded as small family businesses. But with the help of globalization food retailing in Turkey has dramatically increased. While some factors like, urbanization, evolving life styles of individuals, and education level helped demand side of this growth, other factors like government support policies and foreign direct investments supported the supply side [30].

Although Turkish consumers have been shopping primarily from small markets and grocery stores, the market share of traditional retailers has been steadily eroding, because customers preferences are moving towards mass grocery retailers. Due to this fast growing nature of the industry, the aim of this study is to forecast the sales revenue of grocery retailing industry in Turkey with the help of grocery retailers marketing costs, gross profit, and its competitors' gross profit by using artificial neural network.

Turkish grocery retail industy is segmented. There are different types of markets, which attract different types of customers. Multi-format retailers, regional supermarkets, discount retailers and convenience stores can be identified as the types of grocery retailers in Turkey. Because of this variety, this sector is very fragmented and four largest companies at this sector couldn't reach one fifth of the total revenues.

It is very difficult to reach all the companies that are operating at grocery retailing industry in Turkey. Sampling is determined to overcome this issue. Turkish Stock Exchange is used for sampling. There are 5 major players which are listed at the Turkish Stock Exchange (Borsa Istanbul). These include Kiler, Migros, Carrefour, BİM and Adese. In ANN's there should be enough data to build a strong learning algorithm. In order to maintain that goal quarterly reports are used from the beginning of 2010 until the last quarter of 2013. Because there is no enough data for Kiler and Adese, these companies are subtracted from the study. As a result this study's sample consists of BİM, Migros, Carrefour. Information about these firms, number of store and type of outlet are shown in Table I.

TABLE I: THE GROCERY RETAILING SECTOR PROFILE IN TURKEY

\begin{tabular}{|l|l|l|l|}
\hline \multicolumn{1}{|c|}{ Company name and ownership } & \multicolumn{1}{c|}{ Information about firm } & $\begin{array}{c}\text { Number of store and type of outlet } \\
\text { (2013) }\end{array}$ \\
\hline Migros (Turkish and UK) & $\begin{array}{l}\text { This is the first and oldest grocery retailer in Turkey. Founded in } \\
1954 . \text { The majority of the shares }(50.8 \%) \text { of Migros was taken } \\
\text { over by British BC Partners in 2008. }\end{array}$ & $\begin{array}{l}919 \text { store, } 6 \text { different format, Largest } \\
\text { multi-format retailer in Turkey } \\
\text { with a revenue of } 7 \text { billion TL }\end{array}$ \\
\hline Bim (Turkish, Saudi Arabia and USA) & $\begin{array}{l}\text { This discount market is founded at 1995, and its business style is } \\
\text { similar to ALDI in Germany. }\end{array}$ & $\begin{array}{l}3751 \text { store, Discount format retailer, } \\
\text { Largest retailer in Turkey with a } \\
\text { revenue of 12 billion TL }\end{array}$ & 243 store, Multi format retailer, 3 \\
\hline CarrefourSA (Turkish and French) & This retailer started its operations in Turkey as a single store & $\begin{array}{l}\text { different formats, 2.6 billion revenue } \\
\text { in sales }\end{array}$ \\
\hline
\end{tabular}

Artificial neural network models are preferred to accomplish the sales forecast at recent years. Production and sales costs can allocated with the help of this forecast. As discussed earlier, neural networks are used for different reasons in marketing. Customer service, prospect identification and segmentation etc. are some of the areas that use artificial neural network in marketing. ANN is used as a method that shows its superiority in some studies [16], [31], [32]. As described at the previous chapter, marketing costs, gross profits, and competitors gross profits are identified as the inputs that can affect sales revenue of the upcoming period, and the ANN model is build on this perspective.

An important but difficult problem is to determine the optimal number of hidden layers in ANN [33]. This is true fact that by taking suitable number of hidden layers and the number of neurons in each hidden layer, better results in less training time can be obtained [34]. According to Karsoliya, there are some rules that are used for determining the number of neurons in the hidden nodes [34]:

- The number of hidden layer neurons is $2 / 3$ (or $70 \%$ to $90 \%$ ) of the size of the input layer.

- The number of hidden layer neurons should be less than twice of the number of neurons in input layer.

- The size of the hidden layer neurons is between the input layer size and the output layer size

In order to forecast the sales revenues with $\mathrm{ANN}$, in one hidden layer, two neurons are used as shown in Fig. 1.

NeuroXL add-on is used on Excel in order to implement neural network system to forecast upcoming sales revenue. For training purposes, the period from the first quarter of 2010 until the third quarter of 2013 is used. And for the prediction the last quarter without actual sales revenue is used and with these data, sales revenue is forecasted and compared with the actual data for the same period. The analysis with the help of ANN is conducted at March 2014. 


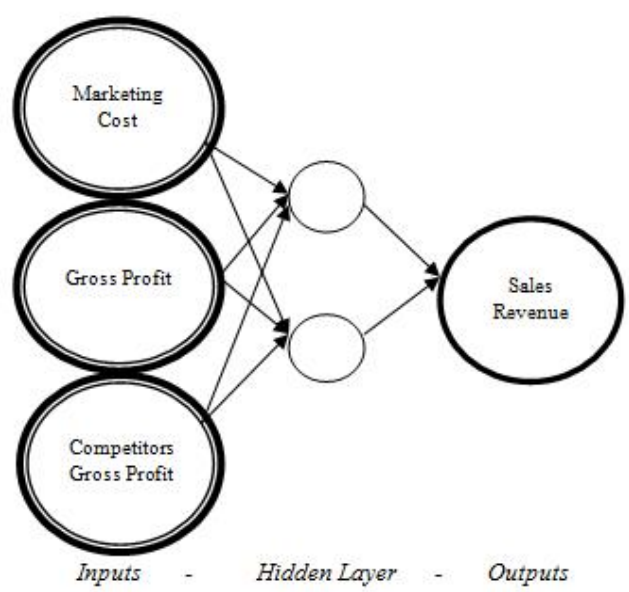

Fig. 1. Neural network of predicting sales revenue.

BİM, Migros and Carrefour's marketing costs, gross profit, competitors gross profit, sales revenue, forecasted sales revenue of each grocery retailer is shown below at the Table II between 2010 and 2013 quarterly. Only these three factors are taken into account in this study. Because of the limitations in accessing related data, the other factors that could affect sales revenue are ignored. Sales revenue just used for training the data.

Because of there is no linear relationship between variables, in one hidden layer two neurons are implemented to the model. Backpropagation is preferred as a method for training in this model. For training, limit of epochs is assigned at 3000 and minimum weight delta is set its default value which is 0,000001 . For prediction, initial weight and learning rate is set at 0,30 while momentum is set at 0,60 . These values are used because this estimate gives the better results. Hyperbolic tangent function is used because positive and also negative data are used as inputs.

As shown in Table II, BİM is the biggest discounted market in Turkey, and leader at the grocery retail industry in Turkey with 12 billion revenue in sales in 2013. This company started its operations at 1995 and rapidly grown since. When looked at closely, its sales revenue is almost always raised.

\begin{tabular}{|c|c|c|c|c|c|c|c|c|}
\hline Retailer & Years & Period & Marketing Costs & Gross Profit & Comp. Gr. Profit & Sales Revenue & Sim. & 2013 - 4 A. S.R. \\
\hline \multirow[t]{16}{*}{ BїM } & 2010 & 1 & -163.570 .000 & 267.505 .000 & 491.830 .366 & 1.575 .876 .000 & & \\
\hline & 2010 & 2 & -176.362 .000 & 253.689 .000 & 520.061 .646 & 1.553 .942 .000 & & \\
\hline & 2010 & 3 & -186.917 .000 & 289.678 .000 & 610.731 .630 & 1.720 .326 .000 & & \\
\hline & 2010 & 4 & -181.956 .000 & 293.807 .000 & 512.638 .197 & 1.723 .807 .000 & & \\
\hline & 2011 & 1 & -191.991 .000 & 313.712 .000 & 523.920 .331 & 1.877 .948 .000 & & \\
\hline & 2011 & 2 & -205.410 .000 & 305.922 .000 & 437.145 .847 & 1.935 .859 .000 & & \\
\hline & 2011 & 3 & -221.168 .000 & 343.758 .000 & 552.955 .001 & 2.160 .396 .000 & & \\
\hline & 2011 & 4 & -217.093 .000 & 345.938 .000 & 553.496 .981 & 2.214 .932 .000 & & \\
\hline & 2012 & 1 & -234.689 .000 & 378.704 .000 & 523.460 .979 & 2.427 .968 .000 & & \\
\hline & 2012 & 2 & -253.386 .000 & 369.571 .000 & 556.259 .959 & 2.352 .881 .000 & & \\
\hline & 2012 & 3 & -265.083 .000 & 402.799 .000 & 624.104 .967 & 2.543 .820 .000 & & \\
\hline & 2012 & 4 & -261.895 .000 & 408.140 .000 & 602.544 .313 & 2.581 .698 .000 & & \\
\hline & 2013 & 1 & -280.387 .000 & 434.359 .000 & 565.181 .407 & 2.795 .492 .000 & & \\
\hline & 2013 & 2 & -290.960 .000 & 442.027 .000 & 587.254 .456 & 2.833 .595 .000 & & \\
\hline & 2013 & 3 & -314.800 .000 & 493.432 .000 & 676.651 .023 & 3.087 .557 .000 & & \\
\hline & 2013 & 4 & -311.238 .000 & 487.513 .000 & 684.671 .784 & 2.971 .580 .509 & $94,87 \%$ & 3.132 .197 .000 \\
\hline \multirow[t]{13}{*}{ Carrefour } & 2010 & 1 & -10.705 .399 & 134.523 .366 & 624.812 .000 & 601.756 .889 & & \\
\hline & 2010 & 2 & -16.371 .507 & 138.436 .646 & 635.314 .000 & 574.286 .361 & & \\
\hline & 2010 & 3 & -27.076 .906 & 149.136 .630 & 751.273 .000 & 642.092 .271 & & \\
\hline & 2010 & 4 & -9.568 .516 & 129.444 .197 & 677.001 .000 & 627.408 .867 & & \\
\hline & 2011 & 1 & -12.039 .378 & 134.107 .331 & 703.525 .000 & 584.630 .150 & & \\
\hline & 2011 & 2 & -14.472 .333 & 133.208 .847 & 609.859 .000 & 565.191 .365 & & \\
\hline & 2011 & 3 & -13.022 .598 & 146.627 .001 & 750.086 .000 & 649.951 .075 & & \\
\hline & 2011 & 4 & -12.389 .599 & 159.084 .981 & 740.350 .000 & 646.089 .123 & & \\
\hline & 2012 & 4 & -11.614 .208 & 164.279 .313 & 846.405 .000 & 653.654 .782 & & \\
\hline & 2013 & 1 & -11.656 .880 & 143.138 .407 & 856.402 .000 & 584.686 .913 & & \\
\hline & 2013 & 2 & -11.775 .436 & 131.358 .456 & 897.923 .000 & 611.439 .988 & & \\
\hline & 2013 & 3 & -12.241 .909 & 153.944 .023 & 1.016 .139 .000 & 681.481 .391 & & \\
\hline & 2013 & 4 & -7.828 .685 & 190.615 .784 & 981.569 .000 & 645.952 .939 & $89,35 \%$ & 722.925 .484 \\
\hline Migros & 2010 & 1 & -246.861 .000 & 357.307 .000 & 402.028 .366 & 1.434 .086 .000 & & \\
\hline
\end{tabular}




\begin{tabular}{|c|c|c|c|c|c|c|c|}
\hline 2010 & 2 & -286.818 .000 & 381.625 .000 & 392.125 .646 & 1.537 .811 .000 & & \\
\hline 2010 & 3 & -339.380 .000 & 461.595 .000 & 438.814 .630 & 1.790 .246 .000 & & \\
\hline 2010 & 4 & -266.458 .000 & 383.194 .000 & 423.251 .197 & 1.602 .981 .000 & & \\
\hline 2011 & 1 & -297.537 .000 & 389.813 .000 & 447.819 .331 & 1.575 .319 .000 & & \\
\hline 2011 & 2 & -186.386 .000 & 303.937 .000 & 439.130 .847 & 1.064 .549 .000 & & \\
\hline 2011 & 3 & -274.155 .000 & 406.328 .000 & 490.385 .001 & 1.613 .335 .000 & & \\
\hline 2011 & 4 & -272.606 .000 & 394.412 .000 & 505.022 .981 & 1.499 .909 .000 & & \\
\hline 2012 & 1 & -268.970 .000 & 385.240 .000 & 516.924 .979 & 1.454 .768 .000 & & \\
\hline 2012 & 2 & -299.390 .000 & 413.799 .000 & 512.031 .959 & 1.552 .452 .000 & & \\
\hline 2012 & 3 & -324.494 .000 & 468.051 .000 & 558.852 .967 & 1.825 .431 .000 & & \\
\hline 2012 & 4 & -310.647 .000 & 438.265 .000 & 572.419 .313 & 1.649 .751 .000 & & \\
\hline 2013 & 1 & -302.790 .000 & 422.043 .000 & 577.497 .407 & 1.590 .678 .000 & & \\
\hline 2013 & 2 & -338.026 .000 & 455.896 .000 & 573.385 .456 & 1.720 .517 .000 & & \\
\hline 2013 & 3 & -367.223 .000 & 522.707 .000 & 647.376 .023 & 2.000 .737 .000 & & \\
\hline 2013 & 4 & -342.240 .000 & 494.056 .000 & 678.128 .784 & 1.904 .503 .692 & $104,93 \%$ & 1.814 .993 .000 \\
\hline
\end{tabular}

Migros is the largest multi factor retailer in Turkey with 7 billion revenue in sales in 2013. This is the first and oldest grocery retail store in Turkey. As seen in Table II, this retailer's gross profit is increasing at a steady pace, but its sales revenue is not changing at the same direction. This is because of cost per unit sold is increasing .

Carrefour is another big player in the Turkish grocery retail business with 2.6 billion revenue in sales in 2013 . Because of the tough competition, this company's sales revenue did not change much through years.

Forecasts are very strong for each retailer. The results of forecasted sales revenue on actual sales revenue rates for retailers are as follows: for BİM (94.87\%) (Fig. 2 in Appendix), for Carrefour (89.35\%) (Fig. 3 in Appendix), and for Migros (104.93\%) (Fig. 4 in Appendix). These strong similarity rates can be interpreted as ANN is suitable tool for forecasting sales revenue at grocery retailing industry.

If marketing costs, gross profit and competitors gross profit stays the same, the forecasted sales revenues of each company for the first quarter of 2014 is as follows; for BİM (3.098.697.398 TL), for Carrefour (720.487.615 TL), and for Migros (1.848.710.093 TL).

\section{CONCLUSION}

Sales forecasting is very crucial for every company, especially for big ones. This process is very complex because there are a lot of factors that should be taken into account. In order to implement reachable goals and successfully achieve them, companies are keen on to predict next periods sales.

Compared to other methods, ANNs are organic, and this method builds a learning algorithm to predict results better. In this study sales revenue forecasts are very close to actual sales revenues for each firm.

Other factors that could affect sales revenue can be also put into the mix at further researchs. Also in this study only grocery retailing industry is analysed. In order to get a big picture, other industry's can be analysed at Turkey. And also, to compare the efficiency of the ANN for sales revenue, country-wise comparison can be done.

\section{APPENDIX}

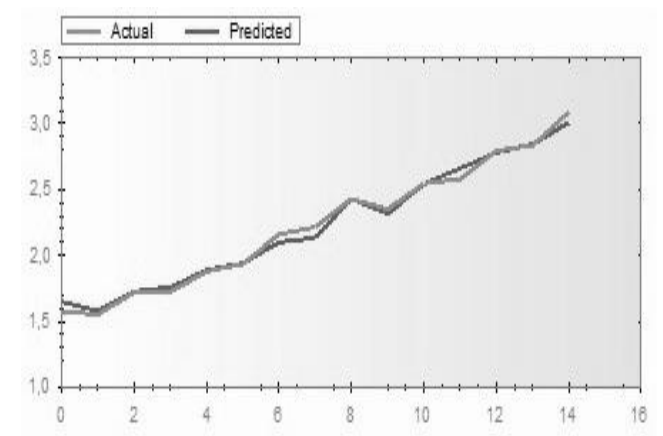

Fig. 2. Bım's Actual and Predıcted Sales Revenue (Billion Tl vs. Time Period).

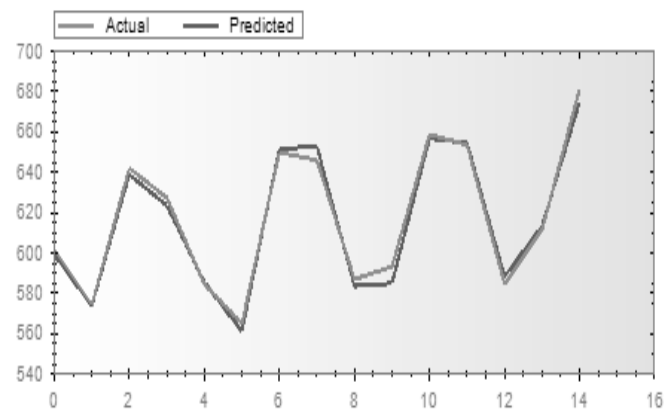

Fig. 3. Carrefour's Actual and Predicted Sales Revenue (Millıon Tl vs. Time Period).

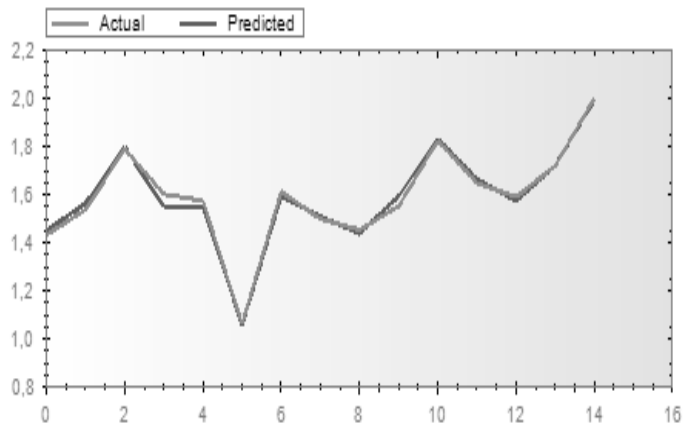

Fig. 4. Migros's Actual and Predıcted Sales Revenue (Bıllıon Tl. vs. Tıme Period). 


\section{REFERENCES}

[1] D. C. Park, M. A. El-Sharkawi, R. J. Marks II, L. E. Atlas, and M. J. Damborg, "Electric load forecasting using an artificial neural network 1991," IEEE Transactions on Power Engineering, vol. 6, pp. 442-449.

[2] D. Specht, “A general regression neural network '1991' A General Regression Neural Network," IEEE Transactions on Neural Networks, vol. 2, no. 6, pp. 568-576.

[3] P. Zhang, Neural Networks in Business Forecasting, USA: Idea Group Inc., 2003, ch. 1.

[4] G. Zhang, E. Patuwo, and M. Hu, "Forecasting with artificial neural networks: The state of the art," International Journal of Forecasting, vol. 14, 1998, pp. 35-62.

[5] A. Kumar, R. Vithala, and S. Harsh, "An empirical comparison of neural network and logistic regression models," Marketing Letters, vol. 6, no. 4, pp. 251-263, 1995.

[6] G. Gianluigi, I. Prete, S. Miraglia, and I. De Mare, "Targeting direct marketing campaigns by neural networks," Journal of Marketing Management, vol. 27, pp. 992-1006, 2011.

[7] R. S. Sexton, R. E. Dorsey, and N. A. Sikander, "Simultaneous optimization of neural network function and architecture algorithm," Decision Support Systems, 2004, vol. 36, pp. 283-96.

[8] H. Harald, "Determining market response functions by neural network modeling: A comparison to econometric techniques," European Journal of Operational Research, vol. 66, pp. 27-35, 1993.

[9] K. Smith and J. Gupta, "Neural networks in business: techniques and applications for the operations researcher," Computers \& Operations Research, vol. 27, pp. 1023-1044, 2000.

[10] B. Curry and L. Moutinho, "Neural networks in marketing: modeling consumer responses to advertising stimuli," Eur. J. Marketing, vol. 27, no. 7, pp. 5-20, 1993.

[11] G. Zahavi and N. Levin, "Applying neural computing to target marketing," J. Direct Marketing, vol. 11, no. 4, pp. 76-93, 1997.

[12] M. Y. Hu, M. Shanker, and S. M. Hung, "Estimation of posterior probabilities of consumer situational choices with neural network classifiers," Int. J. Res. Marketing, vol. 16, no. 4, pp. 307-317, 1999.

[13] G. Zhang, M. Hu, B. E. Patuwo, and D. C. Indro, "Artificial neural networks in bankruptcy prediction: general framework and cross validation analysis," European Journal of Operations Research, vol. 116, no. 1, pp. 16-32, 1999.

[14] Y. S. Kim, N. W. Street, J. G. Russell, and F. Menczer, "Customer targeting: a neural network approach guided by genetic algorithms," Management Science, vol. 51, no. 2, pp. 264-276, 2005.

[15] H. Hruschka, "Using a heterogeneous multinomial probit model with a neural net extension to model brand choice," Journal of Forecasting, vol. 26, no. 2, pp. 113-127, 2007.

[16] D. Agrawal and C. Schorling, "Market share forecasting: an empirical comparison of artificial neural networks and multinomial logit model," Journal of Retailing, vol. 72, no. 4, pp. 383-407, 1996.

[17] V. Venugopal and W. Beats, "Neural networks and statistical techniques in marketing research: A conceptual comparison,' Marketing Intelligence \& Planning, vol. 12, no. 7, pp. 30-38, 1994.

[18] T. Ambler and F. Kokkinaki, "Measures of marketing success," Journal of Marketing Management, vol. 13, 1997, pp. 665-678.

[19] M. Dekimpe and D. Hanssens, "The persistence of marketing effects on sales," Marketing Science, vol. 14, no. 1, pp. 1-21, 1995.

[20] J. A. Weber, "Managing the marketing budget in a cost-constrained environment," Industrial Marketing Management, vol. 31, 2002, pp. 705-717.

[21] D. Reibstein and P. Farris, "Do marketing expenditures to gain distribution cost the customer," European Management Journal, vol. 13, no. 1, 1995, pp. 31-38.

[22] G. S. LeVee, "The key to understanding the forecasting process," Journal of Business Forecasting, vol. 11, no. 4, pp. 12-16, 1992-1993.

[23] G. Johnson and K. Scholes, Exploring Corporate Strategy, 6th Edition, Prentice Hall, 2002.
[24] M. Atalaysun, "USDA foreign agricultural service," Global Agricultural Information Network, December 2011.

[25] T. Zhu, V. Singh, and M. Manuszak, "Market structure and competition in the retail discount industry," Carnegie Mellon University Working Paper, 2007.

[26] G. G. Meyer, "Marketing research and sales forecasting at Schlegel Corporation," Journal of Business Forecasting, vol. 12, no. 2, 1993, pp. 22-23.

[27] C. W. Chase, "Ways to improve sales forecasts," Journal of Business Forecasting, vol. 12, no. 3, pp. 15-17, 1993.

[28] M. M. Florance and M. S. Sawicz, "Positioning sales forecasting for better results," Journal of Business Forecasting, vol. 12, no. 4, 1993, pp. $27-28$.

[29] N. Thall, "Neural forecasts: A retail sales booster," Discount Merchandiser, vol. 32, no. 10, 1992, pp. 41-42.

[30] A. Koç, G. Boluk, and S. Kovaci, "Concentration of food retailing and anti-competitive practices in Turkey," Food Economics - Acta Agriculturae Scandinavica, Section C, vol. 7, iss. 2-4, 2010, pp. 151-162.

[31] P. West, P. Brockett, and L. Golden, "A comparative analysis of neural networks and statistical methods for predicting consumer choice," Marketing Science, vol. 16, no. 4, pp. 370-391, 1997.

[32] F. Kaefer, C. Heilman, and S. Ramenofsky, "A neural network application to consumer classification to improve the timing of direct marketing activities, Computers \& Operations Research, vol. 32, pp. 2595-2615, 2005.

[33] M. Noboru and Y. Shuji, "Network Information Criterion-Determining the Number of Hidden Units for an Artificial Neural Network Model," IEEE Transactions on Neural Network, vol.5, no. 6, pp. 865-872, 1994.

[34] S. Karsoliya, "Approximating number of hidden layer neurons in multiple hidden layer BPNN architecture," International Journal of Engineering Trends and Technology, vol. 31, no. 6, pp.714-717, 2012

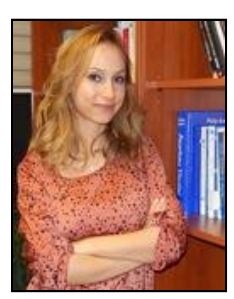

Dilek Penpece was born in Kahramanmaras, Turkey. She earned her BA and MS degrees of business administration from Kahramanmaras Sutcu Imam University at 2003 and 2006. She finished her Ph.D. studies at Cukurova University in the field of Marketing at 2012 in Turkey. Her major field of study is marketing.

She did research assistant job at Kahramanmaras Sutcu Imam University from 2003 until 2006. After that she started working at Cag University at 2009 and worked there until 2012. She earned the title of assistant professor and started working at Adana Science and Technology, and currently working there since. Her current research interests include digital marketing, integrated marketing communication, and crisis communication.

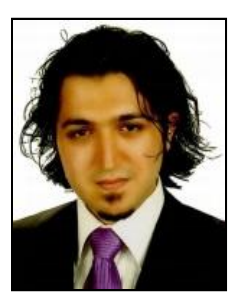

Orhan Emre Elma was born in Konya, Turkey. He earned his BA degree of business administration from Istanbul University at 2008, MBA degree in capital markets and finance from Bahcesehir University at 2011, and he is currently pursuing his Ph.D. degree in finance at Pamukkale University in Turkey. His major field of study is finance.

$\mathrm{He}$ did tourist guiding at New York for two consecutive summers at 2006 and 2007. He enlisted for his military service at 2012. After accomplishing that he did research assistant job at Adnan Menderes University. At 2013, he started working at Adana Science and Technology University as a research assistant and currently working there since. His current research interests include behavioral finance, portfolio management, and capital markets. 